\title{
The Effect of Prenatal Counseling on the Knowledge and Performance About Postpartum Care in Primigravida Women
}

\author{
Farzaneh Soltani $^{1}$, Mehri Esmaeili ${ }^{2}$, Younes Mohammadi ${ }^{3}$, Soodabeh Aghababaei ${ }^{*}$
}

1. Associate Professor, Maternal and Child Care Research Center, Hamadan University of Medical Sciences, Hamadan, Iran

2. School of Nursing and Midwifery, Hamadan University of Medical Sciences, Hamadan, Iran

3. Associate Professor, Faculty of Health, Hamadan University of Medical Sciences, Hamadan, Iran

4. Assistant Professor, Maternal and Child Care Research Center, Hamadan University of Medical Sciences, Hamadan, Iran

\begin{tabular}{lll}
\hline Article Info & ABSTRACT \\
\hline
\end{tabular}

Received: 2019/01/12;

Accepted: 2019/03/10;

Published Online: 2019/08/28

10.30699/sjhnmf.27.5.344

Original Article

Use your device to scan and read the article online

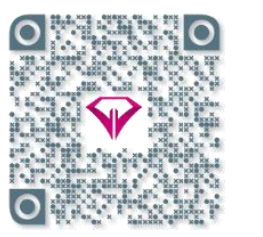

Introduction: The aim of this study was to determine the effect of prenatal counseling on knowledge and practice about postpartum care in primigravida women.

Methods: A quasi-experimental study was conducted in health centers of Hamadan city in 2017. Using a stratified sampling, 96 primigravida women at their 32-34 weeks, were qualified to enter the intervention and control groups. For the experimental group, three 45 minutes weekly counseling sessions were held. Knowledge of postpartum care were gathered by questionnaires before intervention and 42 days after delivery and practice of postpatum care was assessed 42 days after delivery using national Sib Samaneh. Data was analyzed using SPSS 20.

Results: The mean of maternal knowledge scores from postpartum care in the intervention group before and after intervention increased from $17.4 \pm 7.1$ to $33.3 \pm 6.6$ and there was a significant difference with the control group $(20.8 \pm 5.4$ to $21.6 \pm 5.8)$ $(\mathrm{P}<0.001)$. The mean score of mothers' performances on postpartum care in the intervention group was higher than that of the control group $(13 \pm 1 \mathrm{vs} 10 \pm 1 / 9)$, and comparing the two groups, a significant difference was observed $(\mathrm{P}<0.001)$.

Conclusion: The results of this study showed the positive effects of prenatal counseling on increasing the level of knowledge and improving the practice of postpartum care in primigravida women. Therefore, due to various postpartum problems, it is recommended that appropriate education be provided before delivery.

Keywords: Prenatal counseling, Postpartum cares, Primigravida women
Soodabeh Aghababaei, Maternal and Child Care Research Center, Hamadan University of Medical Sciences, Hamadan, Iran. E-mail: aghababaii@yahoo.com

Copyright $\odot$ 2019, This is an original open-access article distributed under the terms of the Creative Commons Attribution-noncommercial 4.0 International License which permits copy and redistribution of the material just in noncommercial usages with proper citation.

\section{How to Cite This Article:}

Soltanni F, Esmaeili M, Mohammadi Y, Aghababaei S. The Effect of Prenatal Counseling on the Knowledge and Performance About Postpartum Care in Primigravida Women. Avicenna J Nurs Midwifery care. 2019; 27 (5) :344-351 


\title{
تأثير مشاوره قبل از زايمان بر دانش و عملكرد زنان نخستباردار درخصوص مراقبتهاى يس از زايمان

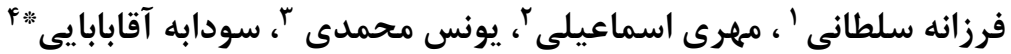

\author{
I. . دانشيار، مركز تحقيقات مراقبتهاى مادر و كودى، دانشكاه علوميزشكى همدان، همدان، ايران

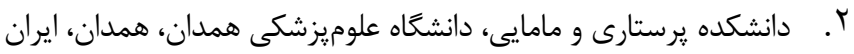

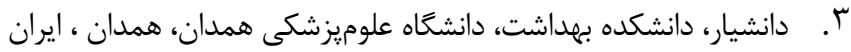

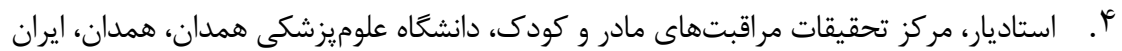

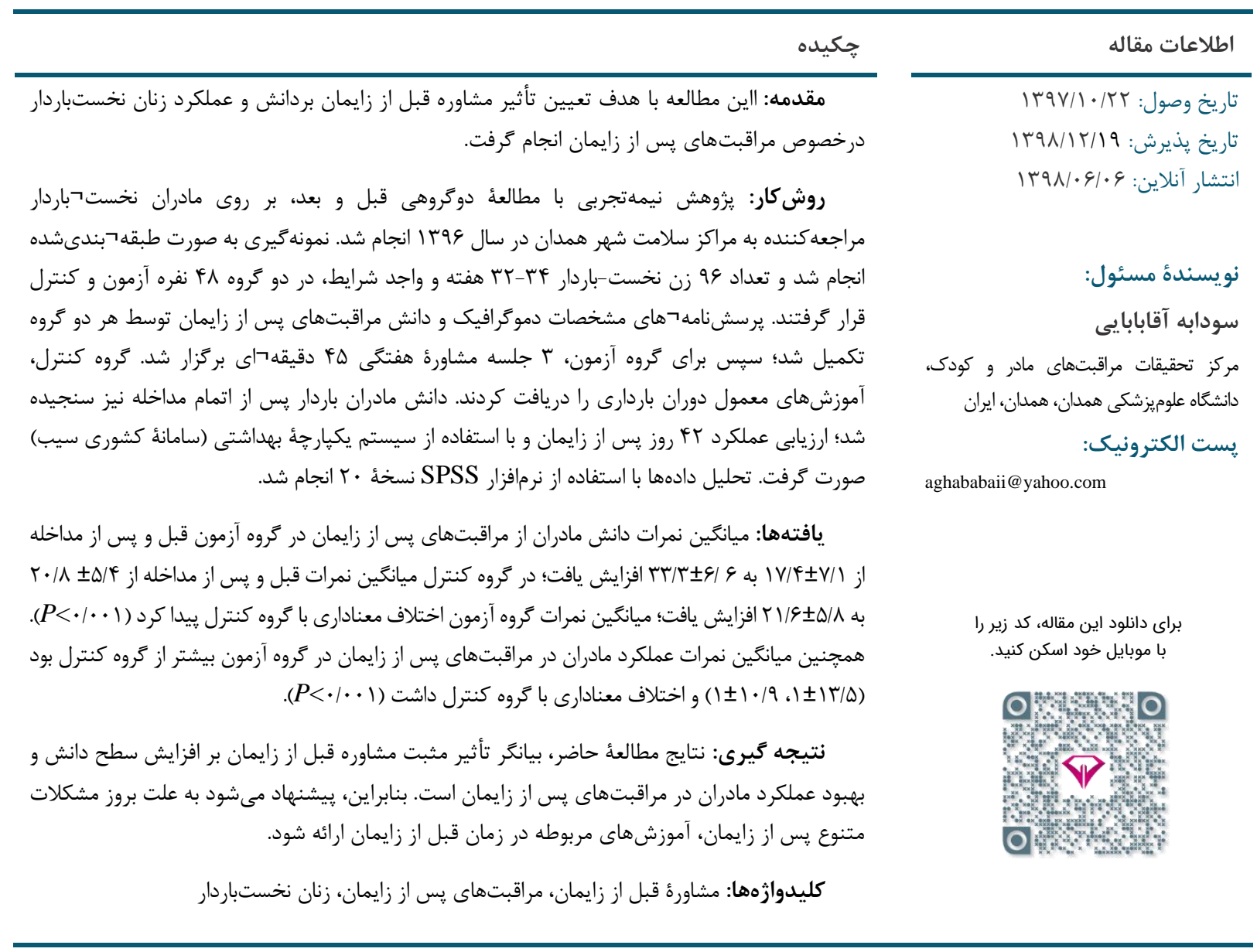

مقدمه

در بيشخيرى از بيامدهاى ناخواستهٔ مادرى و نوزادى باشد. اين

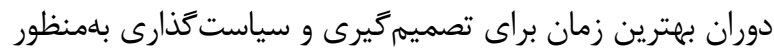

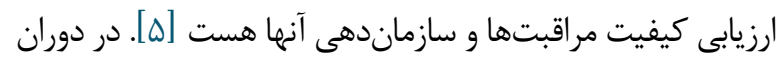

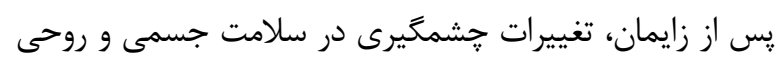
روانى مادران رخ مىدهد كه ميىتواند منجر به كاهش كيفيت

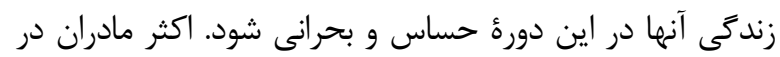

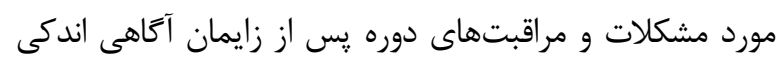

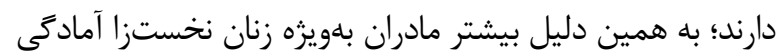
لازم براى مادرشدن ندارند و به حمايت خانواده، دوستان و

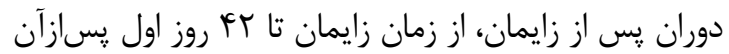

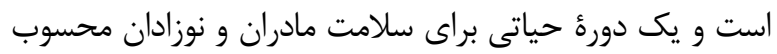

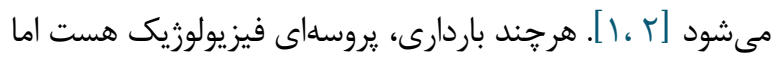

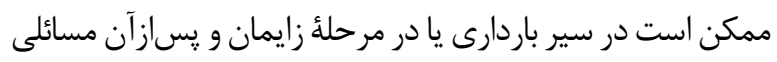

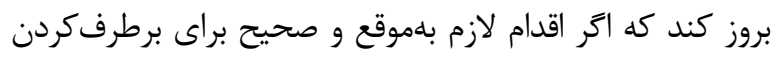

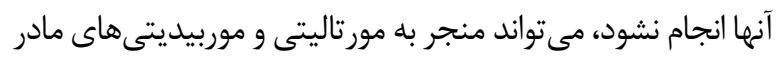

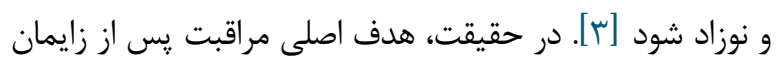

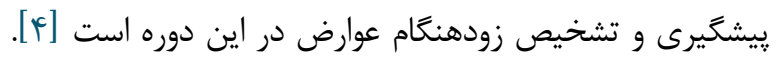

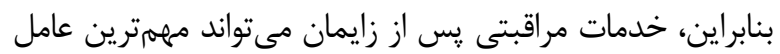


به مراكز سلامت شهرستان همدان در سال و9 انجام شده است.

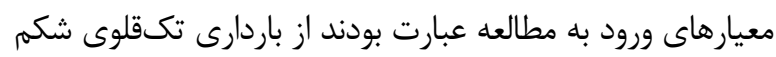

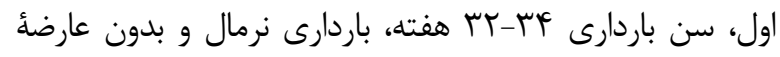

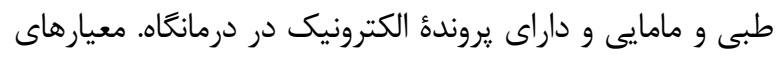

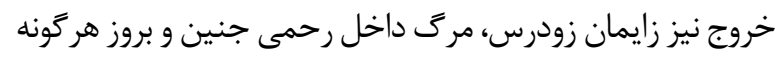

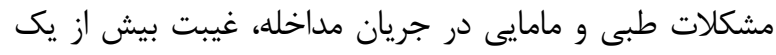
جلسه مشاوره بود.

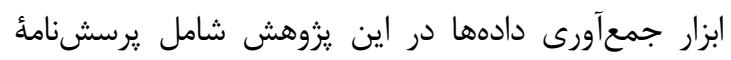

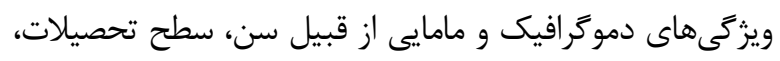

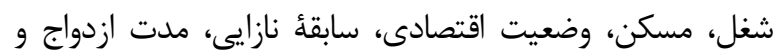

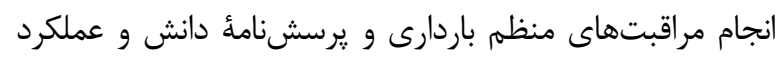

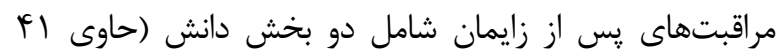

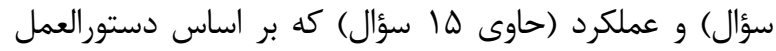

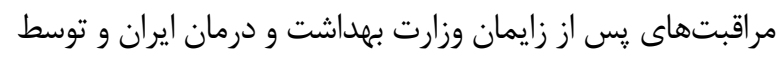

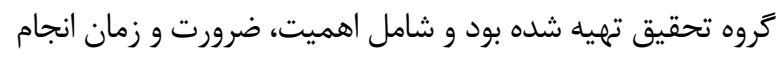
مراقبتهاى يس از زايمان، تغييرات دوران نفاس، علائم خطر و و

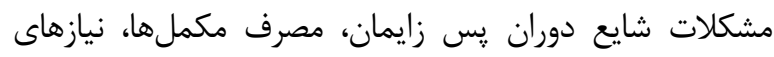

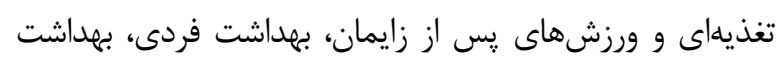
دهان و دندان، شيردهى، مراقبت از نوزاد، واكسيناسيون، تست تيروئيد و زردى در نوزاد بوده است.

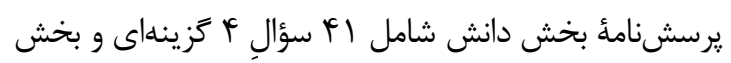
عملكرد شامل ها سؤال r كزينهاى بلى و خير بود. به پاسخهاى صحيح، نمرة يك و به ياسخ غلط، نمرةٔصفر تعلق كرفت و ميانكين

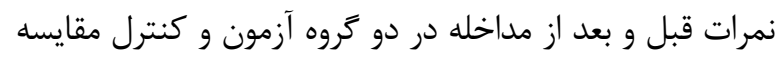

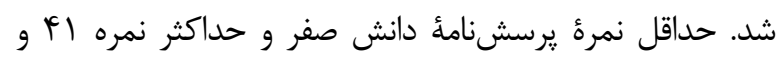

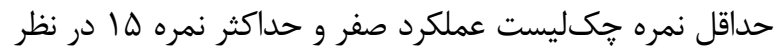

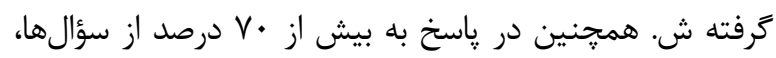

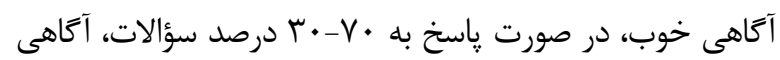

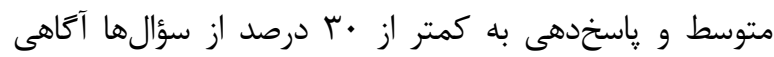
ضعيف اطلاق مىشد.

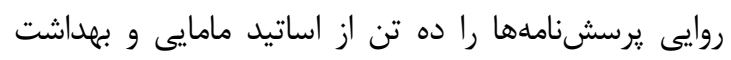

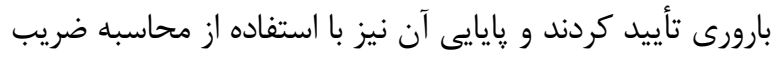

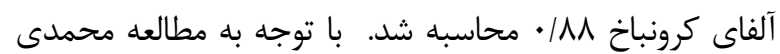

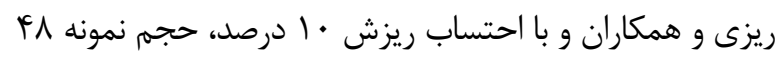

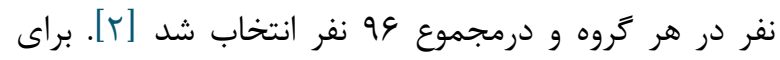

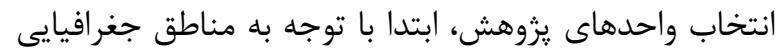

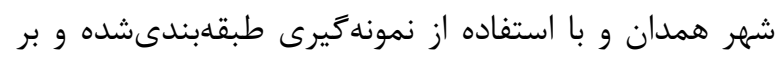

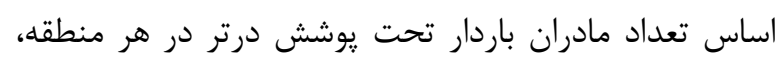

مراقبين بهداشتى نياز دارند [ع]. دوره پِ از زايمان، زمانى مملو

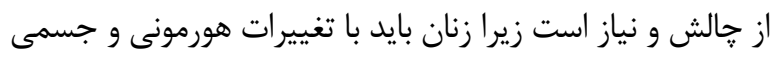
سازكار شوند، از عوارض زايمان بهبود يابند و تغيير مسئوليت هاى

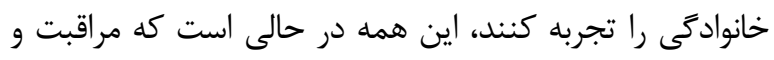

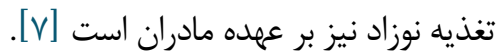
سلامت مادر بهعنوان يكى از شاخصهاى مهيم سلامت جامعله،

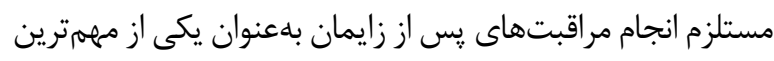

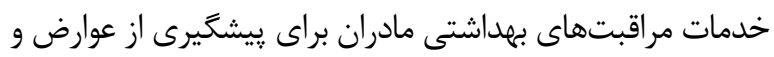
ناتوانىهاى ناشى از زايمان است [N]. مطالعات انجامشده نشان داده است كه وسعت مشكلات مربوط به عوارض يس إن از زايمان در

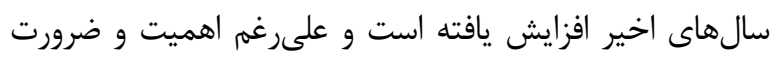
مراقبتهاى يُ از زايمان، در بسيارى از مراكز بهداشتى مراقبت

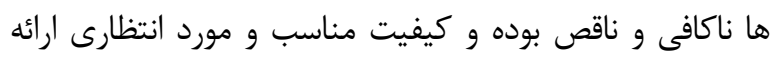

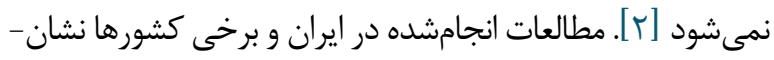

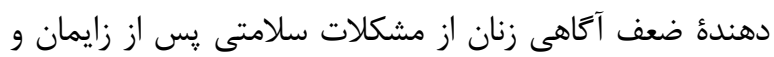
عدم آمادكى مادران براى تجربئ دوران نفاس و درنتيجه فقدان يان إنان

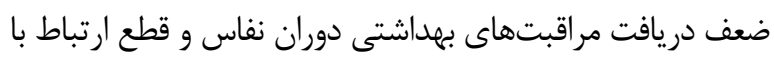

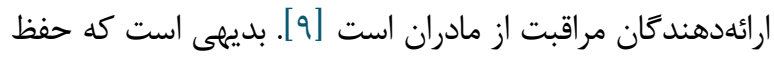
سلامت مادر براى ازسركيرى نقش همسرى، مادرى و اجتماعى رمادى

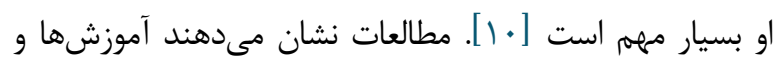

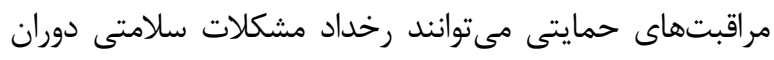

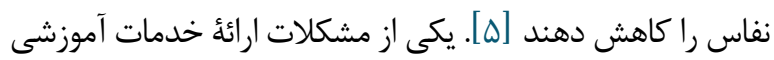

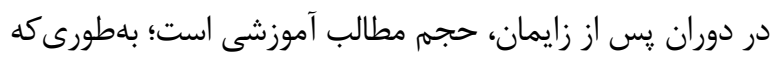

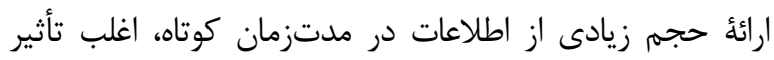

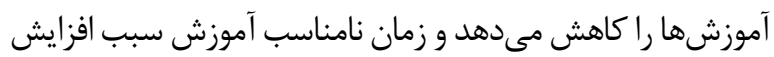

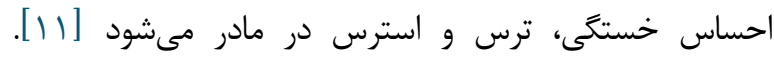

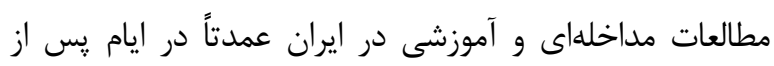

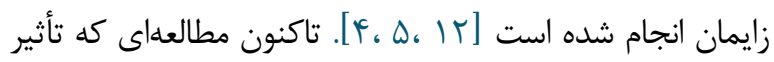

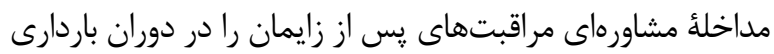

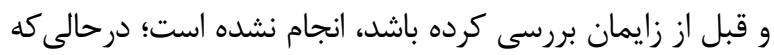

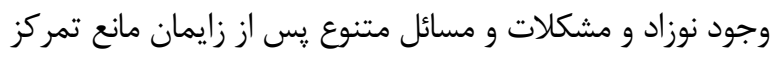
كافى مادران بر آموزشهاى ارائهشده مىشود. بنابراين، مطالعه

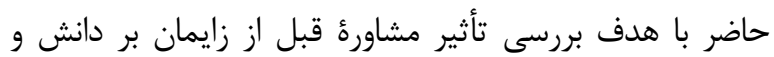
عملكرد زنان نخستباردار در مراقبتهاى بِ إن از زايمان انجام شدر.

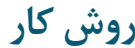

اين يزوهش، يك مطالعهُ نيمهتجربى با مطالعُ دو كروهى قبل

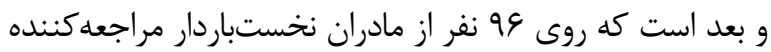


بافتهها

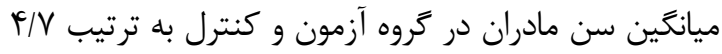
معن

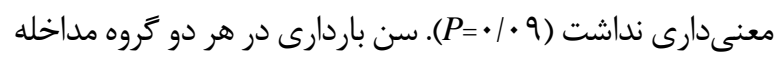

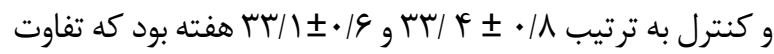

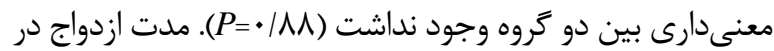

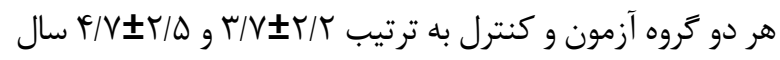

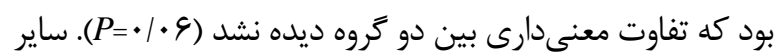
مشخصات دموكرافيك در جدول شماره r نشان داده شده است. براى مقايسٔ دانش مادران نسبت به مراقبتهاى يس إن از

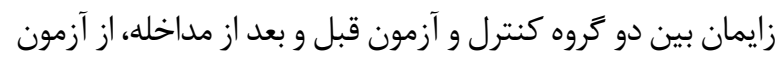

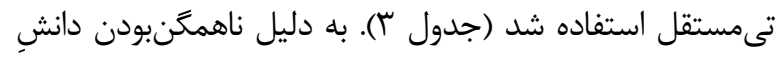

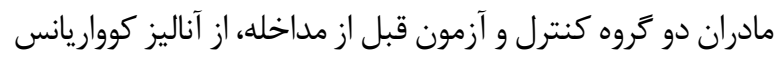

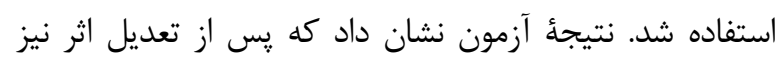
اختلاف معنىدارى بين دانش مادران در دو كروه آزمون و كنترل

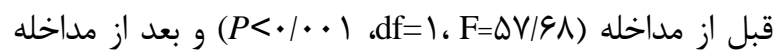
(df=l، $\mathrm{F}=1 \mid \Delta / \Lambda \Lambda)$

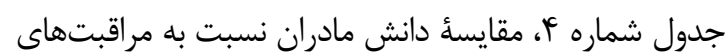
يس از زايمان در هر يك از دو كروه كنترل و آزمون را قبل و بعد إندان

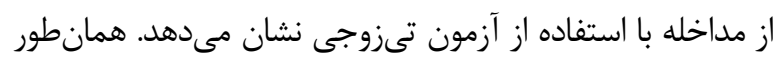

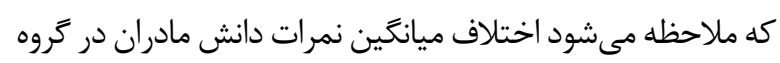

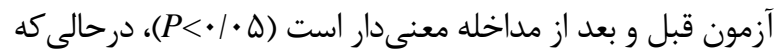

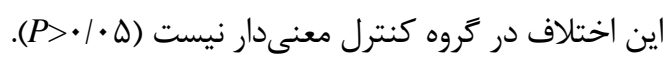

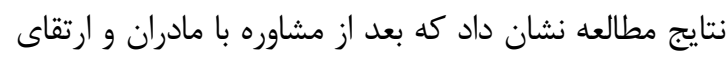
آكاهى آنان، گروه آزمون از سطح عملكرد خوبى درزمينئ

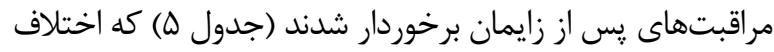

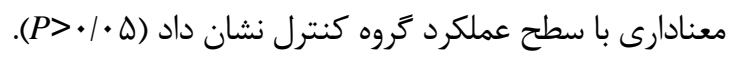

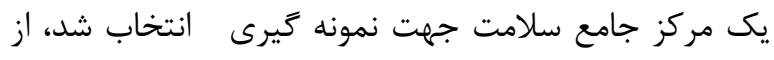

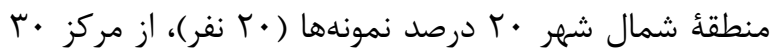

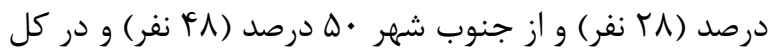

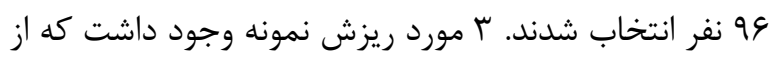
مطالعه خارج شدند؛ سيس با استفاده از روش تصادفى در هر هر

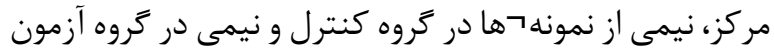

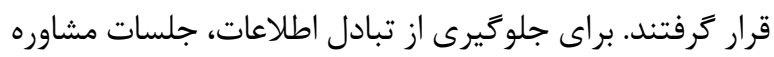

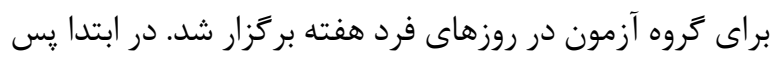
از توضيحات لازم و كسب رضايت آكاهانه، يرسشنامنامجها توسط افراد هر دو كروه آزمون و كنترل تكميل شد و پِ رَس از

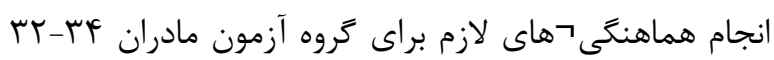

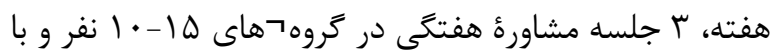

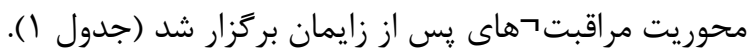

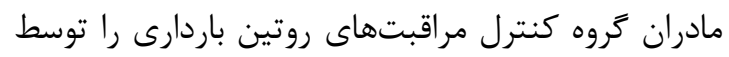

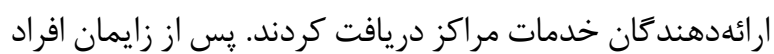

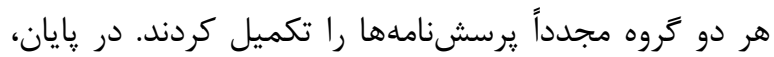

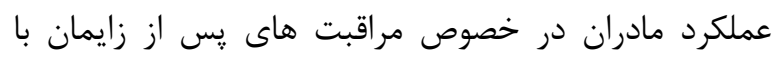

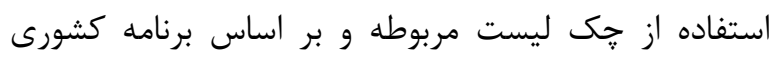
سامانه سيب در هر دو گروه آزمون و كنترل ارزيابى كرديد.

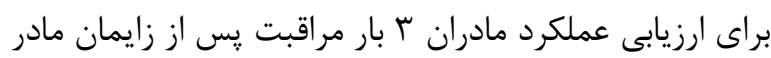

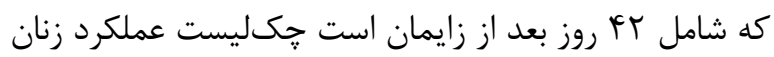

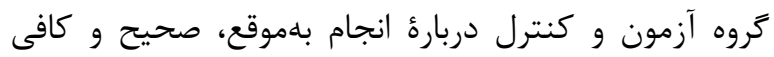
مراقبتهاى يس از زايمان و بر اساس برنامه كشورى سامانه

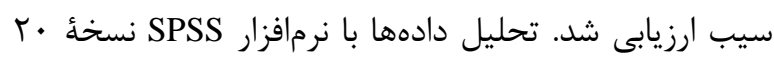

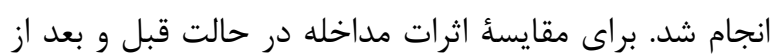

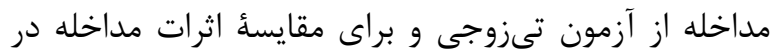

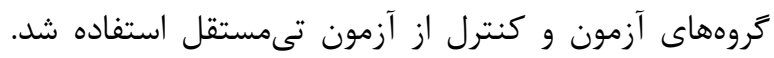

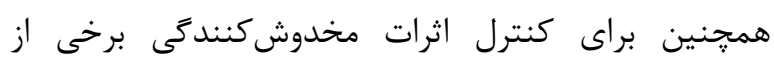

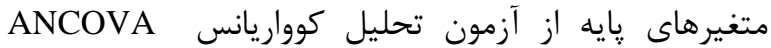

جدول ا محتوى جلسات مشاوره گروهى در خصوص مراقبت هاى يس از زايمان

\begin{tabular}{|c|c|}
\hline محتوا & جلسه \\
\hline 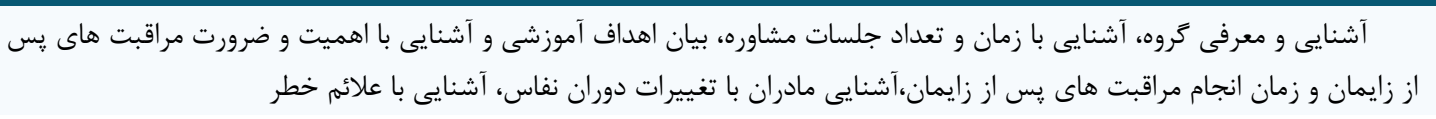 & اول \\
\hline 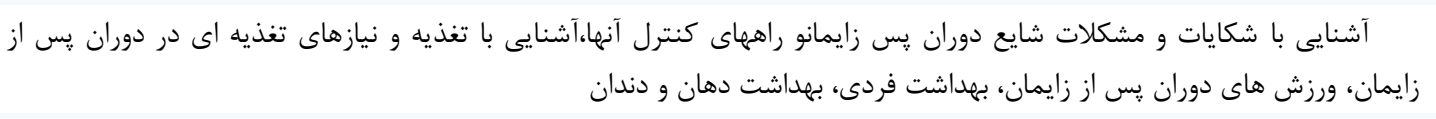 & دوم \\
\hline شيردهى، مراقبت از نوزاد، واكسيناسيون،انجام تست تيروييد نوزادزرردى در نوزاد،مرورى بر مطالب قبل و پاسخ به سوالات & سوم \\
\hline
\end{tabular}


A I ت تأثير مشاورة قبل از زايمان بر دانش و عملكرد زنان نخستباردار

جدول r. مقايسُٔ مشخصات دموكر افيك و مامايى دو گروه

\begin{tabular}{|c|c|c|c|c|c|c|}
\hline \multirow{2}{*}{ P-Value } & \multicolumn{2}{|c|}{ كنترل } & \multicolumn{2}{|c|}{ آزمون } & \multirow[t]{2}{*}{ - ل تروه } & \multirow[b]{2}{*}{ متغير } \\
\hline & درصد & تعداد & درصد & تعداد & & \\
\hline \multirow{2}{*}{$\cdot|r|$} & $\Lambda \mu / r$ & $r$. & $9 \vee / V$ & pF & خانهدار & \multirow{2}{*}{ 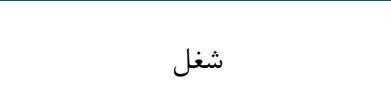 } \\
\hline & $19 / V$ & $\wedge$ & $\Lambda / r$ & r & شاغل & \\
\hline \multirow{4}{*}{$\cdot / \Lambda V$} & $1 \cdot / 4$ & $\Delta$ & $\varepsilon / \Gamma$ & r & سواد خواندن و نوشتن & \multirow{4}{*}{ تحصيلات } \\
\hline & $1 \mathrm{~N} / \mathrm{A}$ & 9 & $r r / q$ & 11 & زير دييلم & \\
\hline & $r V / \Delta$ & 11 & $\mathrm{rV} / \mathrm{Q}$ & 11 & دييلهم & \\
\hline & 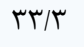 & 19 & 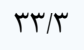 & 19 & دانشكاهى & \\
\hline \multirow[t]{2}{*}{$.1 \cdot 90$} & $r \Delta / \mathcal{F}$ & IV & $\Delta F / T$ & re & شخصى & \multirow{2}{*}{ وضعيت مسكن } \\
\hline & $94 / 9$ & m & $F \Delta / \Lambda$ & rt & استيجارى & \\
\hline \multirow[t]{2}{*}{. } & $9 / \pi$ & r & $9 / \pi$ & r & بله & \multirow{2}{*}{ سابقه نازايى } \\
\hline & $9 \pi / 1$ & $i \Delta$ & $94 / 1$ & id & خير - & \\
\hline \multirow{2}{*}{$\cdot / \Lambda \mathrm{V}$} & $90 / 9$ & rr & $9 \Delta / \Lambda$ & is & بله & \multirow{2}{*}{ مراقبت منظم يرهناتال (حداقل ه بار } \\
\hline & $f \cdot / q$ & $\Delta$ & $r / r$ & r & خير & \\
\hline
\end{tabular}

جدول س. مقايسهُ دانش مادران باردار نسبت به مراقبتهاى يس از زايمان قبل و بعد از مداخله بين دوكروه

\begin{tabular}{|c|c|c|c|c|c|c|}
\hline P-Value & درجة آزادى & $\mathrm{t}$ & انحرافمعيار & ميانگين & تروه & \\
\hline \multirow{2}{*}{$\cdot 1 \cdot 1$} & \multirow{2}{*}{94} & \multirow{2}{*}{ T/GT } & $\omega / \mathcal{F}$ & $r \cdot / \Lambda$ & كنترل & \multirow{2}{*}{ قبل از مداخله } \\
\hline & & & $V / I$ & $I V / F$ & آزمون & \\
\hline \multirow{2}{*}{$\cdot 1 \cdot 1<$} & \multirow{2}{*}{$9 f$} & \multirow{2}{*}{$V / Q$} & $\Delta / \Lambda$ & $r \mid / 9$ & كنترل & \multirow{2}{*}{ بعد از مداخله } \\
\hline & & & $9 / 9$ & r/r & آزمون & \\
\hline
\end{tabular}

جدول F. مقايسُٔ دانش مادران باردار نسبت به مراقبتهاى يس از زايمان قبل و بعد از مداخله در دو كروه

\begin{tabular}{|c|c|c|c|c|c|c|c|}
\hline \multirow{2}{*}{ P-Value } & \multirow{2}{*}{ درجئ آزادى } & \multirow{2}{*}{$\mathbf{t}$} & \multicolumn{2}{|c|}{ بعد از مداخله } & \multicolumn{2}{|c|}{ قبل از مداخله } & \\
\hline & & & انحرافمعيار & ميانگين & انحر افمعيار & ميانگين & \\
\hline $.1 \cdot 1<$ & FV & $9 / 1$ & $9 / 9$ & r/r & $V / I$ & $I V / F$ & آزمون \\
\hline$\cdot / r$ & FV & $1 / \cdot 0$ & $\Delta / \Lambda$ & $r T / G$ & $\Delta / \mathcal{A}$ & $r \cdot / \Lambda$ & كنترل \\
\hline
\end{tabular}

جدول ه. مقايسئ عملكرد مادران دربارهٔ مراقبتهاى پِ از زايمان بين دو كروه

\begin{tabular}{|c|c|c|c|c|c|}
\hline P-Value & درجه آزادى & t t t t & انحراف معيار & ميانتين & عملكرد \\
\hline \multirow{2}{*}{$<\cdot|\cdot|$} & \multirow{2}{*}{$q 4$} & \multirow{2}{*}{ N/IV } & $1 / 0$ & $\mid r / \cdot$ & آزمون \\
\hline & & & $1 / 9$ & $1 \cdot 11$ & كنترل \\
\hline
\end{tabular}


به وضعيت سلامتى مطلوب، تشويق تغذيه با شير مادر و ارائه

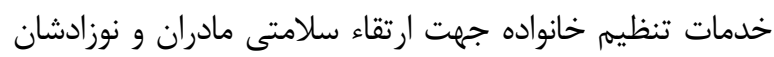

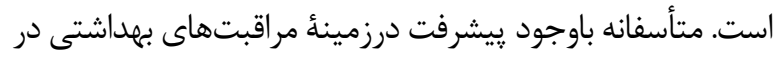

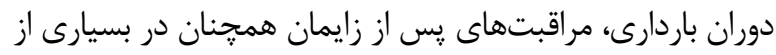

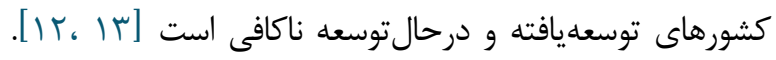

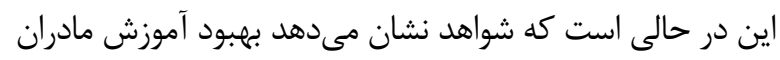

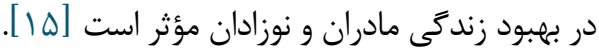
نتايج مطالعهاى در ايالاتمتحده نشان داد بيمارىهان و وران

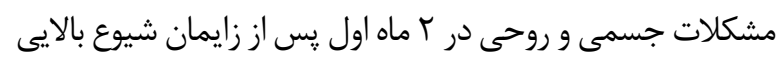
دارد و برنامهريزى براى مراقبتهاى بهداشتى و تشويق حراه

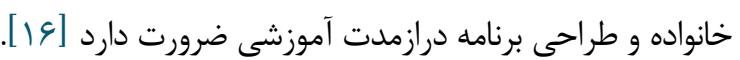

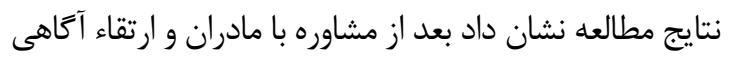

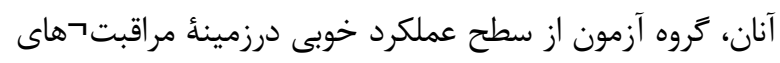

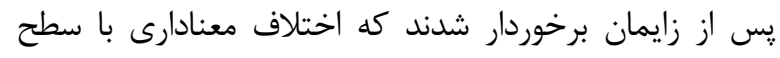

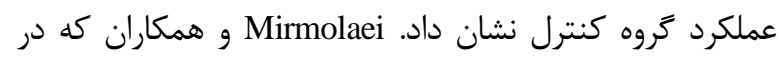

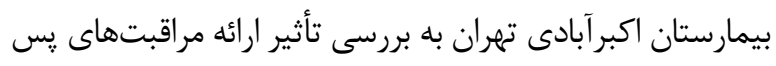

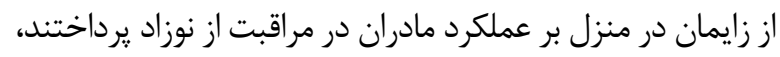

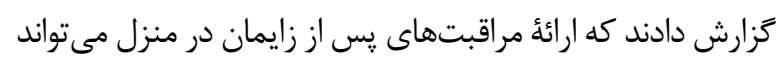

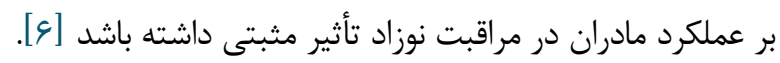

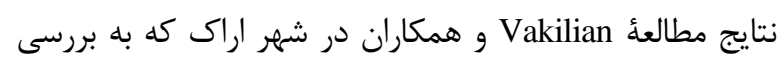

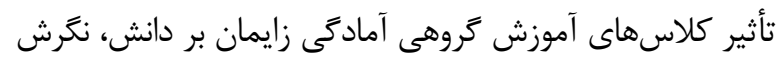

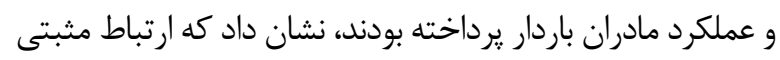

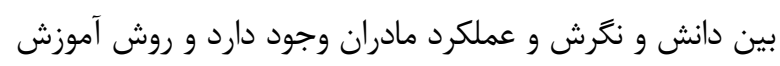

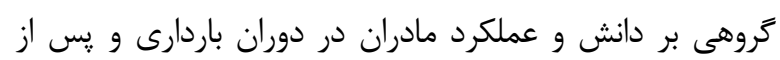

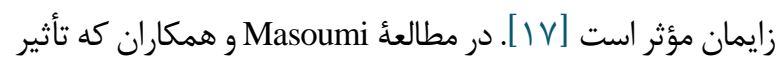

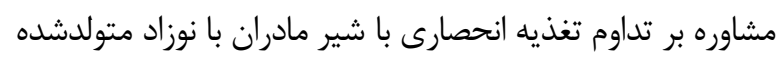

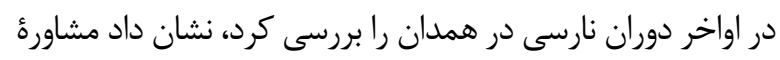

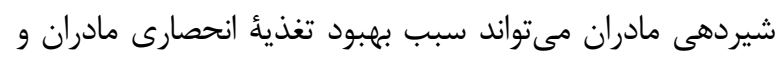

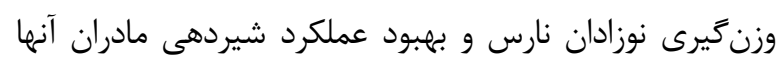

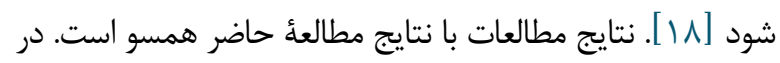

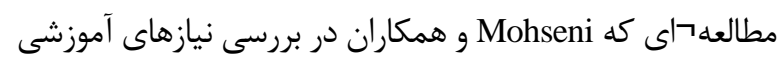

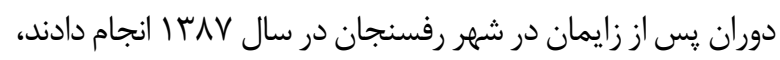

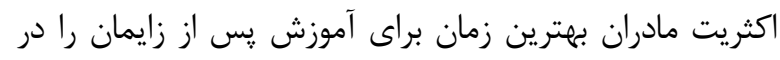

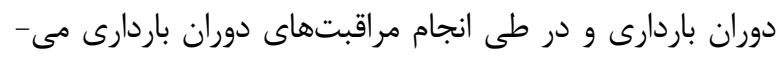

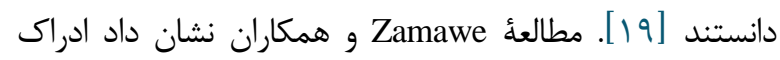

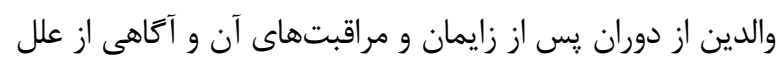

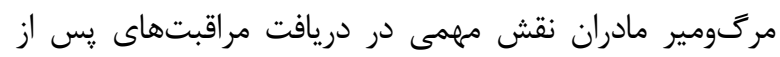

نتايج اين مطالعه كه با هدف تعيين تأثير مشاوره بر دانش و

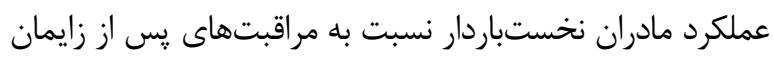

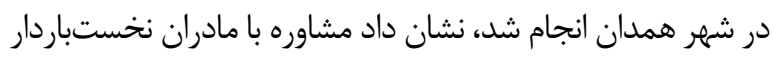

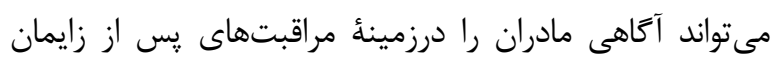

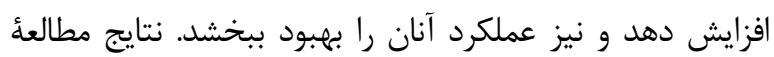

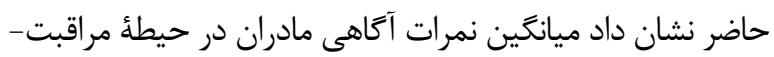

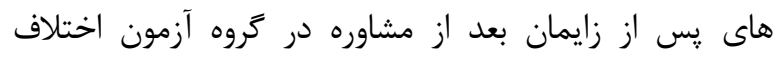

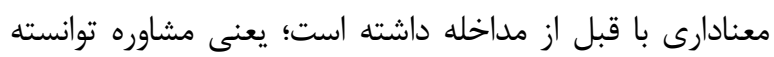

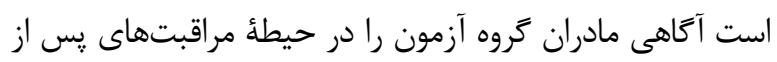
زايمان در ابعاد مختلف افزايش دهد.

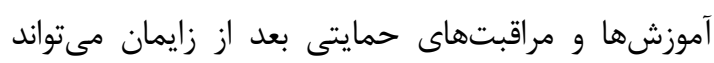

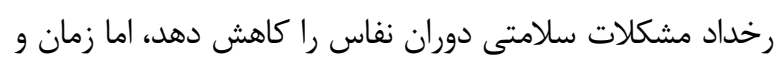

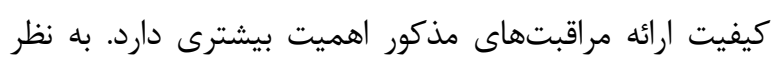

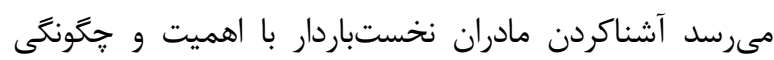

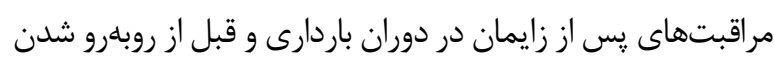

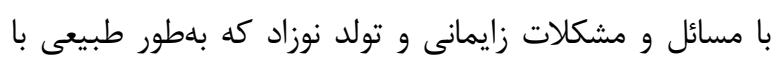

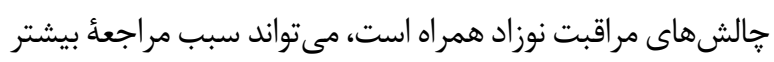

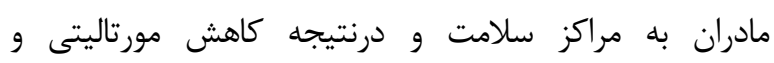

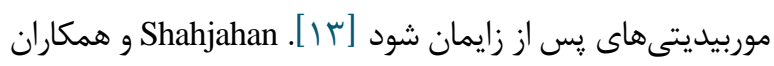

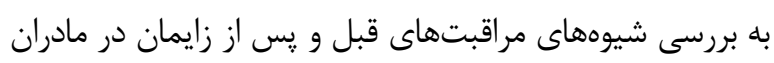

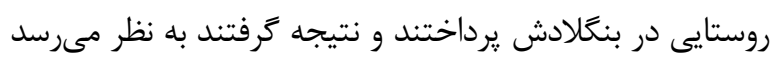

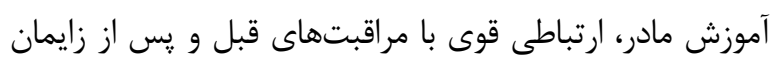

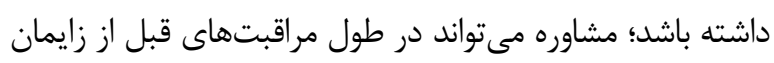

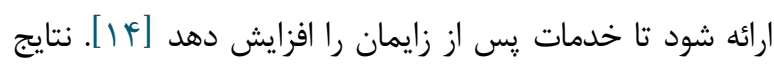

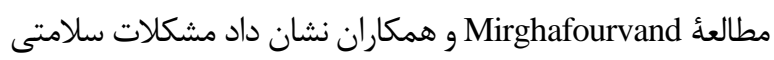
در دوران يّ از زايمان، يبوست، درد شكمه، شقاق نوك يستان،

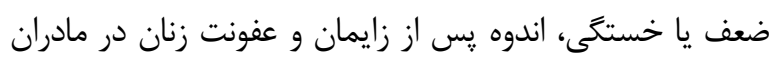

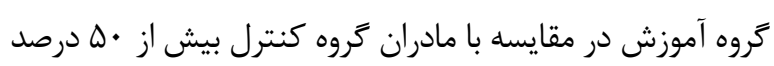

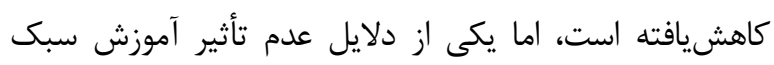

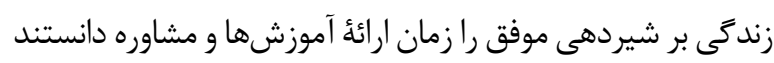

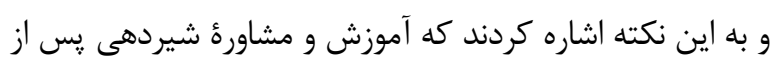

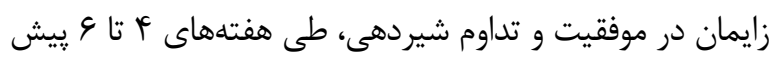

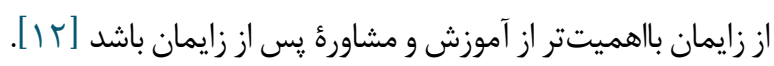
بنابراين، نتايج اين مطالعات با نتايج مطالعُ حاضر همسو است إن.

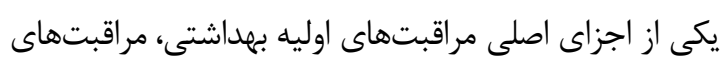

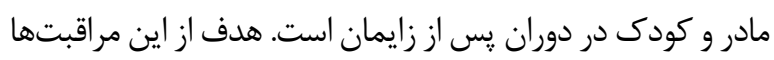

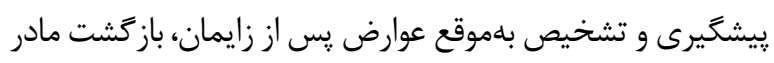


• هَ تأثير مشاورة قبل از زايمان بر دانش و عملكرد زنان نخستباردار

برنامهريزىشده بركزار شود. ارتقاء آكاهى و عملكرد كاركنان

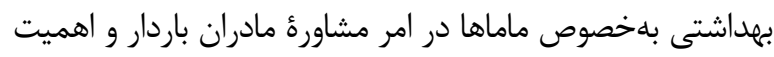
مراقبتهاى يس از زايمان انجام گيرد.

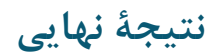

نتايج حاصل از اين مطالعه نشان داد مشاوره دربارة مراقبتهاى يّ از زايمان در دوران باردارى مى إتواند دانش مادران

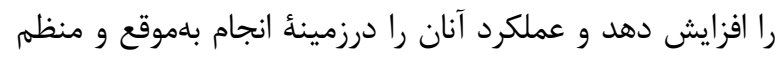
مراقبتهاى يس از زايمان و رعايت اصول مراقبتى خود و نوزاد

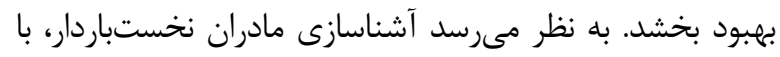

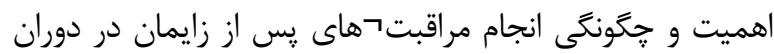

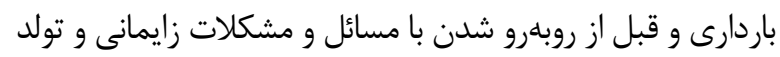

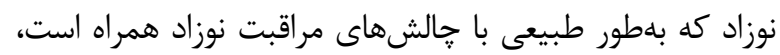
مىتواند سبب مراجعأ بيشتر مادران به مراكز سلامت و درنتيجه

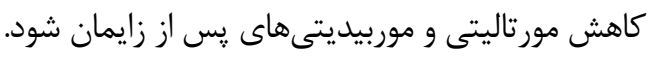

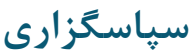

اين مقاله منتج از پايان نامٔ دوره كارشناسى ارشد مصوب

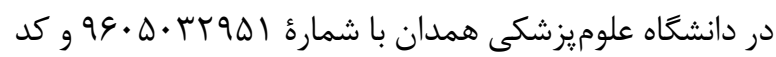

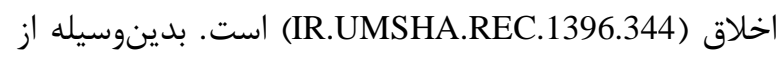
معاونت محترم يزوهشى دانشآاه علوم يزشكى همدان و همأ

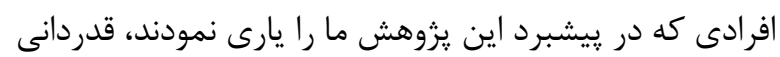

$$
\text { مى كنيم. }
$$

$$
\text { تعارض در منافع }
$$

بين نويسندكان هيجگَونه تعارضى در منافع وجود ندارد

$$
\text { منابع مالى }
$$

منابع مالى اين مطالعه توسط نويسندًان تامين شده است.

\section{References}

1. Milani HS, Amiri P, Mohseny M, Abadi A, Vaziri SM, Vejdani M. Postpartum home care and its effects on mothers' health: A clinical trial. J Res Med Sci 2017; 22:96. [DOI:10.4103/jrms.JRMS_319_17] [PMID] [PMCID]

2. Mohamadirizi S, Bahrami B, Moradi F. Comparison of the effect of electronic educationand pamphlet on the knowledge of women about their post partum hygiene. Journal of Nursing Education. 2015; 3(4):29-36.

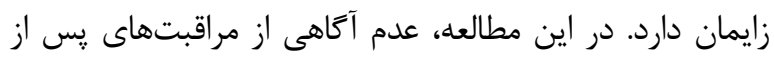

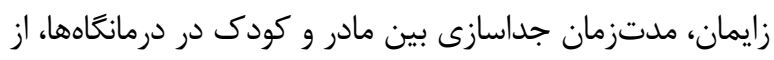

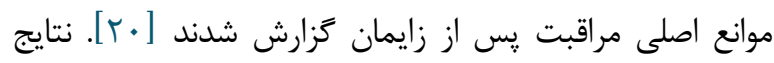

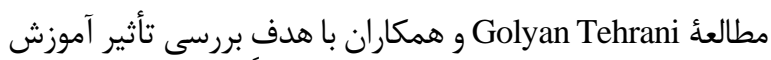

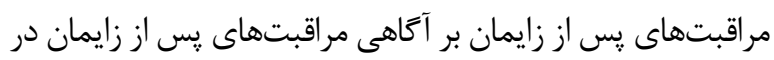

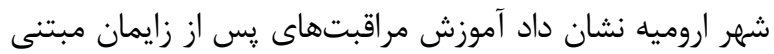

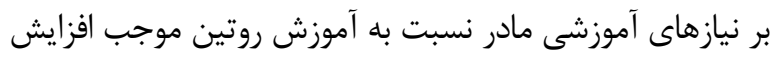

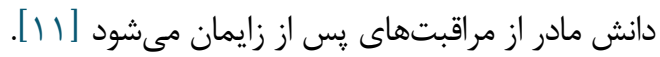

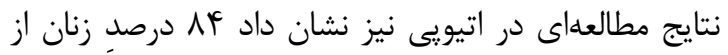

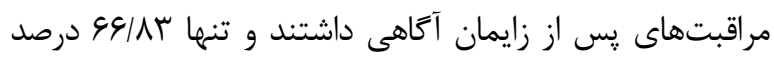

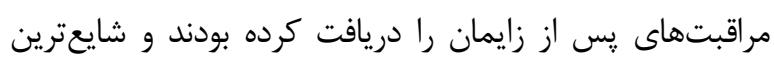

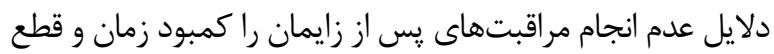

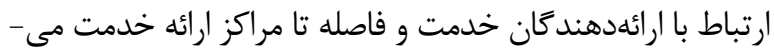

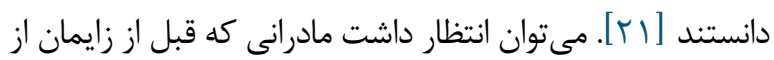

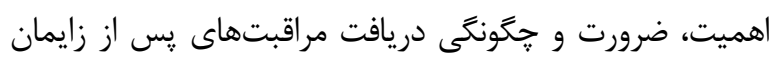

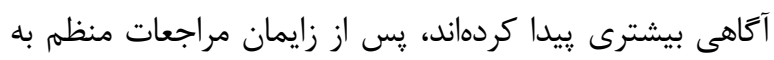

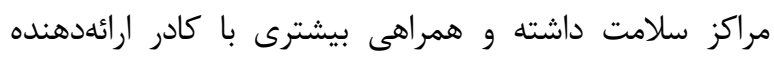

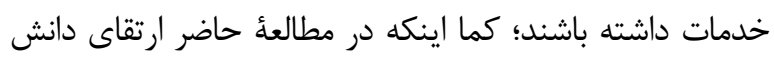

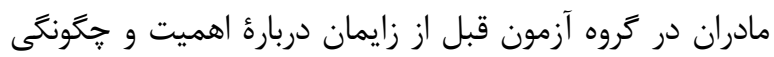

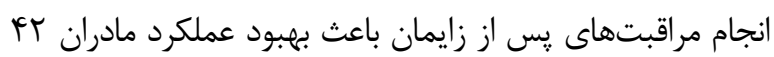

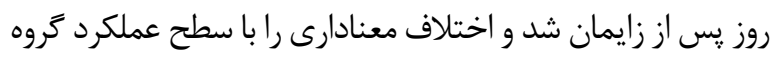

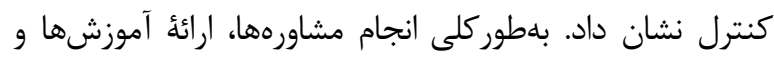

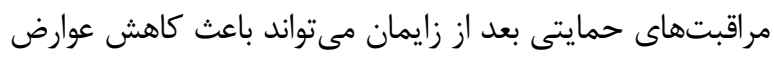

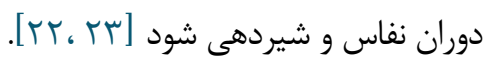
محدوديتهاى اين مطالعه، هماهنتى هاى لازم براى شركت

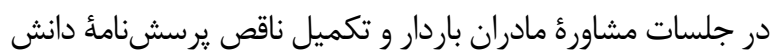

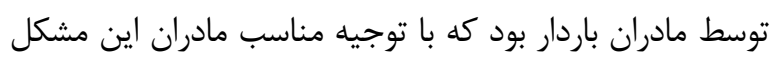

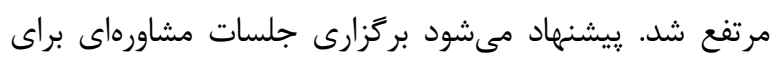

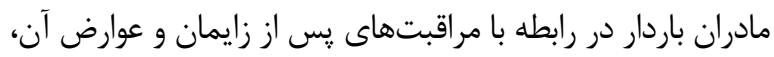

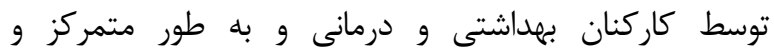

3. Safizadeh M, Damadi B, Safizadeh H. An epidemiologic study of maternal deaths in the population covered by kerman university of medical sciences, 2010-2012. Journal of Health and Development. 2015; 4(2):114-23.

4. Mirzaee K, Taghi Shakeri M. Maternal knowledge on postpartum care in healthcare centers of Mashhad, Iran in 2013. Journal of Midwifery and Reproductive Health. 2015; 3(4):456-64. 
5. Peighambardost R, Fadaiy Z. Effect of telephone support and Women satisfaction of Postpartum care. Journal of Clinical Nursing and Midwifery. 2016; 5(1):36-46.

6. Mirmolaei ST, Valizadeh A, Mahmoudi M, Tavakol Z. Effect of home postpartum care on quality of life of low risk mothers. Hayat. 2011; 17(2):42-51.

7. Tully KP, Stuebe AM, Verbiest SB. The fourth trimester: a critical transition period with unmet maternal health needs. Am J Ob-stet Gynecol. 2017;217(1):37-41. doi:10.1016/j.ajog.2017.03.032.8. Timilsina S, Dhakal R. Knowledge on postnatal care among postnatal mothers. Saudi Journal of Medical and Pharmaceutical Sciences. 2015; 1:87-92. [DOI:10.1016/j.ajog.2017.03.032] [PMID]

8. Kamali Fard M, Mirghafourvand M, Khodabandeh F, Asghari Jafar Abadi M, Mansoori A. Effect of lifestyle educational package on prevention of postpartum health problems in nulliparous mothers: a randomized clinical trial. Journal of Mazandaran University of Medical Sciences. 2016; 25(132):33-48.

9. Jarrah S, Bond AE. Jordanian women's postpartum beliefs: an exploratory study. International Journal of Nursing Practice. 2007; 13(5):289-95. [DOI:10.1111/j.1440-172X.2007.00640.x] [PMID]

10. Golyan Tehrani S, Rahimi Foroushani A, Neisani Samani L. Evaluation of effect of postpartum care education based on maternal education needson knowledge of postpartum care. Journal of Urmia Nursing And Midwifery Faculty. 2017; 15(2):76-85.

11. Mirghafourvand M, Khodabandeh F, Asghari JafarAbadi M, Mansoori A. Effect of lifestyle educational package on prevention of postpartum health problems in nulliparous mothers: a randomized clinical trial. Journal of Mazandaran University of Medical Sciences. 2016; 25(132):33-48.

12. Fikree FF, Ali T, Durocher JM, Rahbar MH. Health service utilization for perceived postpartum morbidity among poor women living in Karachi. Social science \& $\begin{array}{lll}\text { Medicine. } & \text { 2004; }\end{array}$ [DOI:10.1016/j.socscimed.2003.11.034] [PMID]

13. Gennaro S, Thyangatbyanga $\mathrm{D}$, Kersbbaumer R, Thompson J. Health promotion and risk reduction in Malawi, Africa, village women. Journal of Obstetric, Gynecologic, \& Neonatal Nursing. 2001; 30(2):224-30. [DOI:10.1111/j.1552-6909.2001.tb01539.x] [PMID]

14. Shahjahan M, Chowdhury HA, Al-Hadhrami AY, Harun GD. Antenatal and postnatal care practices among mothers in rural Bangladesh: A community based crosssectional study. Midwifery. 2017; 52:42-8. [DOI:10.1016/j.midw.2017.05.011] [PMID]

15. Behal M, Vinayak R, Kumar A. Assessment of mother's knowledge towards pregnancy, childbirth, postpartum and essential newborn care in district Solan, HP. International Journal of Community Medicine and Public Health. 2018; 5(5):2129-37. [DOI:10.18203/23946040.ijcmph20181736]

16. Cheng CY, Fowles ER, Walker LO. Postpartum maternal health care in the United States: A critical review. The
Journal of Perinatal Education. 2006; 15(3):34-42. [DOI:10.1624/105812406X119002] [PMID] [PMCID]

17. Vakilian K, Mobaseri S. The evaluation prenatal preparation classes in knowledge, attitude and practice in pregnant mothers. Nursing Development in Health. 2014; 4(6-7):73-81.

18. Masoumi SZ, Ahmadi S, Parsa P, Roshanaei G, Basiri B. Effects of counseling on adherence to exclusive breastfeeding in mothers of hospitalized late preterm infants in Fatemieh hospital, Hamadan, Iran. Scientific Journal of Hamadan Nursing \& Midwifery Faculty. 2015; 23(3):72-81.

19. Mohseni M, Loripoor M, Nekuei N. Educational needs of postpartum period in women referring to health care centers of Rafsanjan in 2008. Community Health Journal. 2013; 7(1):18-27.

20. Zamawe CF, Masache GC, Dube AN. The role of the parents' perception of the postpartum period and knowledge of maternal mortality in uptake of postnatal care: a qualitative exploration in Malawi. International Journal of Women's Health. 2015; 7:587-94. [DOI:10.2147/IJWH.S83228] [PMID] [PMCID]

21. Tesfahun F, Worku W, Mazengiya F, Kifle M. Knowledge, perception and utilization of postnatal care of mothers in Gondar Zuria District, Ethiopia: a crosssectional study. Maternal and Child Health Journal. 2014; 18(10):2341-51. [DOI:10.1007/s10995-014-1474-3] [PMID] [PMCID]

22. Aghababaei S, Bakht R, Bahmanzadeh M. Effects of breastfeeding education among primiparous women referring to Fathemieh hospital in Hamadan, Iran. Scientific Journal of Hamadan Nursing \& Midwifery Faculty. 2009; 17(12):41-51.

23. Soltani F, Majidi M, Shobeiri F, Parsa P, Roshanaei GH. Knowledge and Attitude of Men Towards Participation in Their Wives' Perinatal Care. International Journal of Women's Health and Reproduction Sciences. 2018; 6(3):356-362. [DOI:10.15296/ijwhr.2018.58] 